\title{
Case study: New evidence of a piriformis variant inserting onto the hip joint capsule
}

\author{
Sebastien Barfoot, S. Ali Mirjalili
}

Barfoot S, Mirjalili AS. Case study: New evidence of a piriformis variant inserting onto the hip joint capsule. Int J Anat Var. 2019;12(4): 50-51.

In this case study we present new evidence of a piriformis muscle variant inserting onto the hip joint capsule similar to that described by Tubbs and Salter. The variant was also atypical in that it originated medial to the first anterior sacral foramina and therefore obscured the union of the S1 nerve root and lumbosacral trunk. We believe this is the first instance that this variant has been noted.

\section{Key Words: Piriformis; Anatomical variation; Hip joint}

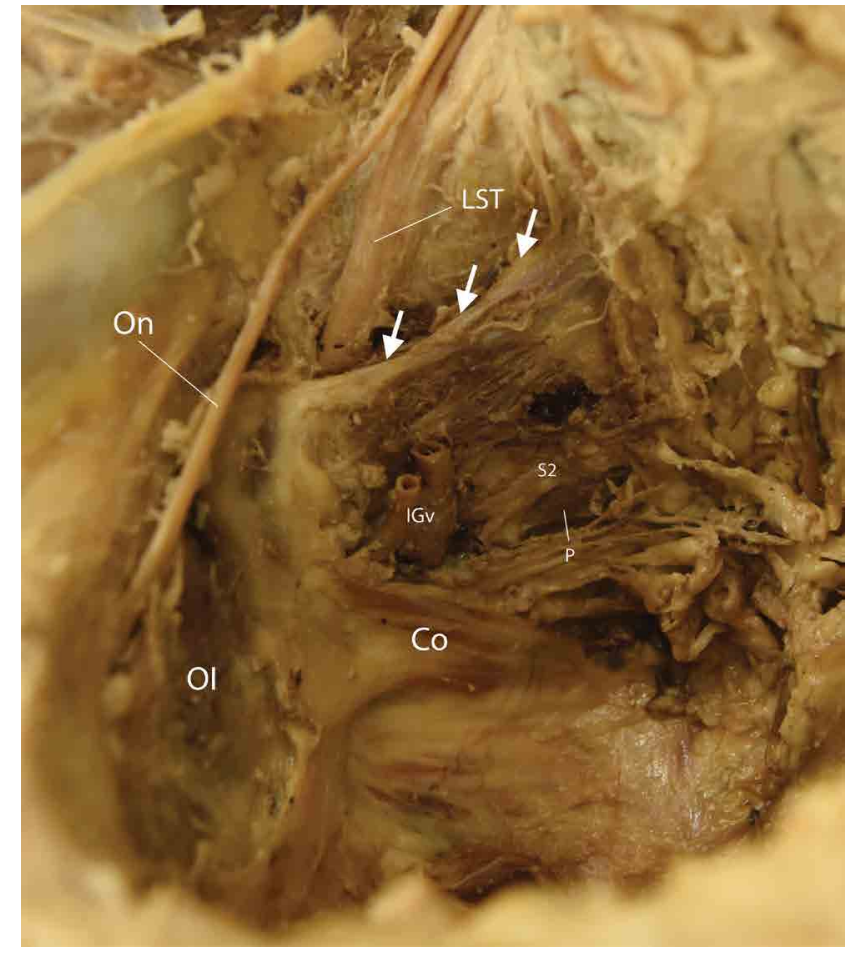

Figure 1) Variant muscle (white arrows showing superior edge) located on right hand side with lumbosacral trunk (LST) passing posteriorly and the inferior gluteal vessels (IGv) passing anteriorly. The origin of the S1 nerve root and the union of the LST with S1 is obscured by the muscle as it attaches medial to the first anterior sacral foramen. Some fibres extend over the second anterior sacral foramen to join true piriformis muscle (P), obscuring the most proximal aspect of the S2 nerve root which then continues anterior to piriformis and inferior to the variant muscle. $\mathrm{Co}=\mathrm{Coccygeus}$ muscle. $\mathrm{OI}=\mathrm{Obturator}$ internus. On=Obturator nerve.

This case differs from the present study however by the fact that the variant muscle originated from the postero-superior GSF, not the sacrum, and compressed the superior gluteal nerve. The authors consequently implicated the potential of this variant muscle to cause neuropathic pain as well as to

Department of Anatomy and Medical Imaging, Faculty of Medical and Health Sciences, University of Auckland, New Zealand

Correspondence: Dr. S. Ali Mirjalili, Department of Anatomy and Medical Imaging, Faculty of Medical and Health Sciences, University of Auckland, New Zealand. Telephone+64-9-3737599; E-mail: s.barfoot@auckland.ac.nz

Received: Jul 18, 2019, Accepted: Oct 22, 2019, Published: Oct 29, 2019 org/licenses/by-nc/4.0/), which permits reuse, distribution and reproduction of the article, provided that the original work is properly cited and the reuse is restricted to noncommercial purposes. For commercial reuse, contact reprints@pulsus.com 


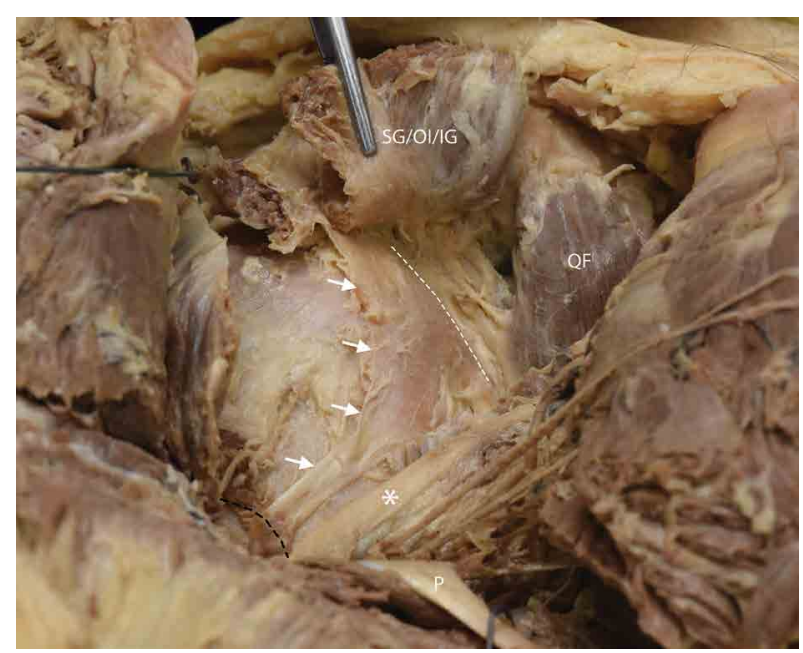

Figure 2) The distal, flattened tendon (white arrows depict superior border) of the right-sided variant muscle is shown fanning out and inserting on the posterior hip joint capsule deep to the sciatic nerve $\left({ }^{*}\right)$ and short external rotators of the hip. Piriformis (P), superior gemellus (SG), obturator internus (OI) and inferior gemellus (IG) have been reflected to open up the region. The acetabular rim is indicated by the white dotted line and the inferior aspect of the greater sciatic foramen is indicated by the black dotted line. QF=Quadratus femoris.

influence hip joint mechanics by exerting tension on the joint capsule.

As in Tubbs and Salter [1], we posit that this muscle may have exerted tension on the posterior joint capsule as it lacked other bony insertion and also that it may have compressed the underlying sacral plexus, although this was not evident in the cadaver's medical records. This notion of this function may further be supported by the somewhat similar muscle iliocapsularis which has been said to play a role in hip joint stability by exerting tension on the joint capsule to which it originates [5-7]. On the left side, lack of a distinct tendon may indicate that the muscle was not truly functional.

\section{DISCUSSION \& CONCLUSION}

Similar cases with slips of piriformis originating medial to the anterior sacral formina exist [8-10], but they are all located at normal vertebral levels corresponding with the piriformis origin (S2-4) and have not been associated with abnormal distal insertions. Smoll and Ebrall [9] noted for the first time grey rami communicantes piercing through the variant anterior slips of piriformis but it was unfortunately not possible to observe this detail in our study.

Origin as high up the sacrum as we found is not reported in the literature as far as we know for piriformis variants and embryological information for piriformis is sparse making it difficult to draw correlation to precursor structures. Furthermore, whilst the literature provides numerous examples of variations in muscle belly number and their distal insertion points, especially in conjunction with sciatic nerve variations and piriformis syndrome [1113], there seems to be a paucity of detail when it comes to reporting the specifics of the proximal origin and many authors and textbooks remain somewhat vague when it comes to stating exactly where piriformis originates on the sacrum. Studies that do state variation in proximal origin are often wildly atypical forms, such as those of Prasad et al [14] and Tubbs and Salter [1] which originated on the GSF and had no sacral attachment or that of Ravinandrath et al [15] where accessory slips were noted in three cadavers originating from the sacrotuberous ligament with or without attachment to the facia over gluteus medius. We suggest that a detailed study of the sacral attachment of piriformis would be of academic value for clarifying its morphology and variability, and in cases of duplicated or triplicated muscle bellies we suggest that detail of their exact origin be investigated if possible.

\section{REFERENCES}

1. Tubbs RS, Salter EG. A variant gluteal muscle. Clin Anat. 2006;19:729.

2. Standring S. Gray's Anatomy: The Anatomical Basis of Clinical Practice (41st Edition). London: Elsevier. 2016;728 \& 1358.

3. Arifoglu Y, Surucu HS, Sargon M, et al. Double superior gemellus together with double piriformis and high division of the sciatic nerve. Surg Radiol Anat. 1997;19:407-8.

4. Nicholson H, Woodley S, Flack N. “Gluteal Muscles” in Bergman's comprehensive encyclopaedia of human anatomic variation. Eds: Tubbs RS, Shoja MM, Loukas M. New Jersey: Wiley Blackwell. 2016;386-409.

5. Ward WT, Fleisch ID, Ganz R. Anatomy of the iliocapsularis muscle. Clin Orthop Relat Res. 2000;374:278-85.

6. Babst D, Steppacher SD, Ganz R, et al. The iliocapsularis muscle: an important stabiliser in the dysplastic hip. Clin Orthop Relat Res. 2011;469:1728-34.

7. Haefeli PC, Steppacher SD, Babst D, et al. An increased iliocapsularisrectus-femoris ratio is suggestive for instability in borderline hips. Clin Orthop Relat Res. 2015;473:3725-34.

8. Lee EY, Margherita AJ, Gierada DS, et al. MRI of piriformis syndrome. Am J Roentgenol. 2004;183:63-4.

9. Smoll N, Ebrall P. The piriformis muscle and its relationship to the autonomics of the pelvis: A single bilateral case. Chiropr J Aus. 2010;40:86-87.

10. Roberts SL, Parente DN, Scallan OH, et al. Variations in sacral nerve root anatomy and their relationship to piriformis: A 3D modeling study. Clin Anat. 2012;25:949; American Association of Clinical Anatomists Meeting, July 8-12, St. George's, Grenada, Abstract/Platform. Clin Anat. 2012.

11. Chen WS. Bipartite piriformis muscle: an unusual cause of sciatic nerve entrapment. Pain. 1994;58:269-72.

12. Kosukegawa I, Yoshimoto M, Isogai S, et al. Piriformis syndrome resulting from a rare anatomic variation. Spine. 2006;31:E664-6.

13. Natsis $\mathrm{K}$, Totlis T, Konstantindis GA, et al. Anatomical variations between the sciatic nerve and the piriformis muscle: a contribution to surgical anatomy in piriformis syndrome. Surg Radiol Anat. 2014;36:273-80.

14. Prasad AM, Nayak BS, Deepthinath R, et al. Clinically important variations in the lower limb - A case report. Eur J Anat. 2005;9:167-9.

15. Ravindranath Y, Manjunath KY, Ravindranath R. Accessory origin of the piriformis muscle. Singapore Med J. 2008;49:E217-8. 